\title{
CT SCAN BASED STUDY OF PNS IN SYMPTOMATIC PATIENTS OF ODISHA
}

\author{
Juli Tudu¹, Geetanjali Arora², Shibanee Jena ${ }^{3}$, Md. Shafique 4 \\ ${ }^{1}$ Assistant Professor, Department of Anatomy, Hi-Tech Medical College and Hospital, Bhubaneswar, Odisha. \\ 2 Professor and HOD, Department of Anatomy, Hi-Tech Medical College and Hospital, Bhubaneswar, Odisha. \\ ${ }^{3}$ Assistant Professor, Department of Anatomy, Hi-Tech Medical College and Hospital, Bhubaneswar, Odisha. \\ ${ }^{4}$ Assistant Professor, Department of Anatomy, Hi-Tech Medical College and Hospital, Bhubaneswar, Odisha.
} ABSTRACT

\section{BACKGROUND}

PNS are in close anatomical relationship with orbit, cranial fossa and pterygopalatine fossa. Pathological lesions of PNS include a wide spectrum of conditions ranging from inflammation to neoplasms. Since clinical assessment is hampered by surrounding bony structures, diagnostic radiology is necessary. CT imaging provides detailed information of PNS.

The objectives of this study were to evaluate the normal anatomical findings of PNS and variations in their pathological lesions and correlate the finding with previous results.

\section{MATERIALS AND METHODS}

This is a descriptive study of 104 patients with pathological lesions of paranasal sinuses.

\section{RESULTS}

A total of 104 patients were studied from January 2016 to December 2017; 2/3 ${ }^{\text {rd }}$ of population were females and chief complaint of headache $(51.9 \%)$ was found. The commonest CT finding were DNS (49\%) and OMU obstructions (70.2\%). Maxillary sinus was more commonly involved (88.5\%).

\section{CONCLUSION}

CT was found to be superior over clinical evaluation of symptomatic patients by providing anatomical details and true local extent of disease for planning different treatment modalities.

\section{KEYWORDS}

PNS (Paranasal Sinus), CT (Computed Tomography), OMU (Osteomeatal Unit), Concha Bullosa, DNS (Deviated Nasal Septum).

HOW TO CITE THIS ARTICLE: Tudu J, Arora G, Jena S, et al. CT scan based study of PNS in symptomatic patients of Odisha. J. Evolution Med. Dent. Sci. 2018;7(11):1409-1412, DOI: 10.14260/jemds/2018/320

\section{BACKGROUND}

Hippocrates in $5^{\text {th }}$ century B. C. stated "In a person having a painful spot in head with intense headaches, pus or fluid running from the nose removes the disease," which may be referred to as describing sinusitis. Pathological lesions of PNS include a wide spectrum of conditions ranging from inflammation to neoplasms, both benign and malignant. Conventional plain radiography readily demonstrates maxillary and frontal sinus disease. They provide limited views of the anterior ethmoid cells, the upper $2 / 3^{\text {rd }}$ of nasal cavity and frontal recess. CT demonstrates the anatomical details and true local extent of the disease, which is essential in choosing the appropriate treatment modality.

Nose develops from olfactory placodes in the 4 th week of intrauterine life.(1,2) Maxillary sinus develops as shallow groove expanding laterally from the infundibulum. At birth sinus has commenced invasion of maxilla, expansion and pneumatisation continue till 8 - 9 yrs. of age. Ethmoids arise from preformed furrows between folds on the lateral wall of nose. Frontal sinus is absent at birth and becomes obvious at

'Financial or Other Competing Interest': None.

Submission 01-02-2018, Peer Review 27-02-2018,

Acceptance 05-03-2018, Published 12-03-2018.

Corresponding Author:

Dr. Juli Tudu,

Assistant Professor, Department of Anatomy,

Hi-Tech Medical College and Hospital,

Bhubaneswar, Odisha.

E-mail: julitudumurmu01@gmail.com

DOI: $10.14260 /$ jemds $/ 2018 / 320$
6 - 12 months of age. Sphenoid sinus is recognisable as an invagination of sphenoethmoidal recess. $(3,4,5)$

Maxillary sinus is hollow pyramidal in shape, based medially on nasal cavity and projects laterally to form apex in zygoma, has 4 walls and 4 processes. $(6,5,7)$ Ethmoidal labyrinth is interposed between the maxilla and anterior cranial fossa is a complicated assemblage of small air cells and fills the region between two orbits. It is related superiorly to frontal lobe, olfactory bulb; laterally to orbit; posteriorly to optic canal; and medially to nasal cavity.(8) Sphenoid sinus invade greater and lesser wings and medial and lateral pterygoid plates of sphenoid, occasionally into basilar part of occipital bone. Frontal sinus found in the frontal bone above and deep to superciliary arch.

Mastery of sinus anatomy and its variant features forms the basis from which radiologic interpretation begins. Familiarisation with radiological landmarks and crosssectional anatomy on patient- CT scans along with clinical correlation can further enhance reader's ability to understand sinus CT findings. $(9,10)$

CT scanning has allowed the radiologists to image paranasal sinus disease with accuracy and details never before attainable. This information has made the imager an important member among the physician team that evaluates the operability and treatment planning of these patients.

CT scan is the appropriate radiological examination of patients with acute sinusitis associated with complications. With experience, CT findings can be accurately correlated with anatomical and clinical findings of a particular patient. 


\section{MATERIALS AND METHODS}

\section{Sources of Data}

The study was carried out with patients referred to Department of Radiology at Hi-Tech Medical College and Hospital extending from January 2016 to December 2017 who were clinically suspected for paranasal sinus diseases. After obtaining clinical history, relevant clinical examinations were done, and patients were subjected to CT PNS. This is a descriptive study of 104 patients with pathological lesions of paranasal sinuses.

\section{Inclusion Criteria}

All the patients with clinically suspected PNS disease.

\section{Exclusion Criteria}

All other lesions mimicking paranasal sinus diseases. All traumatic conditions requiring paranasal sinus CT.

\section{Technique}

Scans were performed with GE Synergy Plus Spiral CT Scanner. For all cases studied, patients were put in supine position for axial sections and were in prone position for coronal sections. For coronal studies, sections were taken from posterior margin of sphenoid sinus to anterior margin of frontal sinus. For axial studies, sections were taken from hard palate to upper margin of frontal sinus. The angulation was parallel to hard palate for axial sections and perpendicular to hard palate for coronal sections. Thickness of $5 \mathrm{~mm}$ was used for axial and coronal sections. After this the CT findings were entered in the proforma prepared.

\section{RESULTS}

All patients were aged between 15 to 75 years' age group. Maximum patients belonged to age group of 21 to 30 years. Two-third of patient's population, i.e. $64.4 \%$ was found to be females. And M:F ratio was almost 1: 1.8, i.e. almost 2 female persons were involved as compared to the involvement of one male person. The commonest complaints in PNS disease patients were headache (51.9\%), nasal discharge (50\%), nasal obstruction (41.3\%) and swelling (1.9\%). The commonest CT findings were DNS (49\%) and OMU obstruction (70.2\%). Maxillary sinus was found to be most commonly involved followed by anterior ethmoid, posterior ethmoid, frontal and sphenoidal sinus.

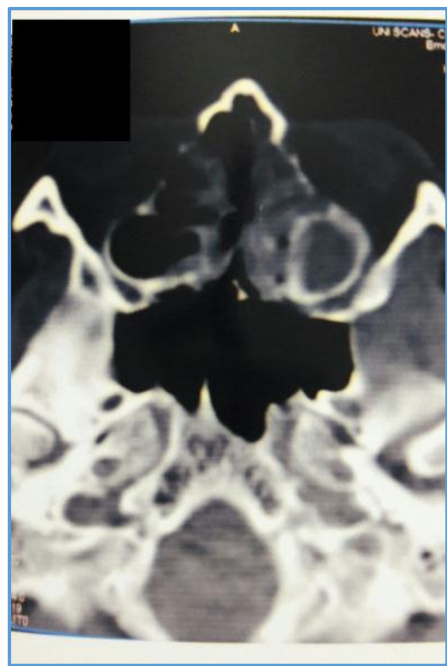

Figure 1. CT Images showing Left Anterior, Middle, Posterior Ethmoidal Sinusitis

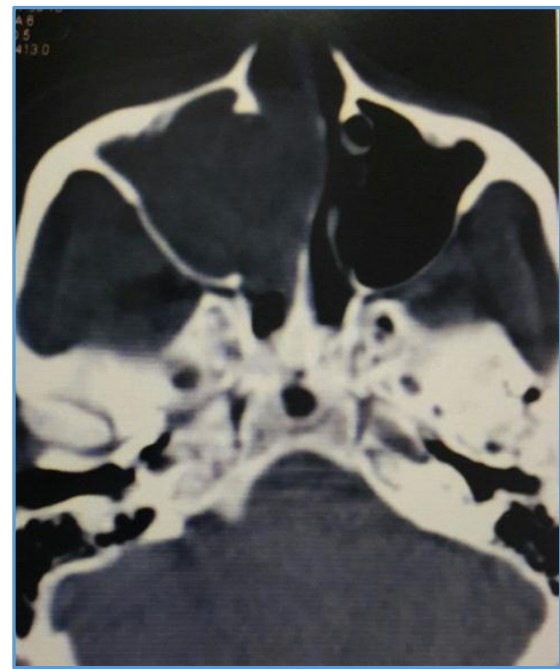

Figure 2. CT Images showing Maxillary Sinusitis and DNS

\begin{tabular}{|c|c|c|}
\hline Age in Years & Number & $\mathbf{\%}$ \\
\hline $11-20$ & 14 & 13.5 \\
\hline $21-30$ & 34 & 32.7 \\
\hline $31-40$ & 25 & 24.4 \\
\hline $41-50$ & 20 & 19.2 \\
\hline $51-60$ & 06 & 5.8 \\
\hline$>60$ & 05 & 4.8 \\
\hline Mean \pm SD & 104 & 100 \\
\hline \multicolumn{2}{|c|}{ Table 1. Age Distribution of Patients Studied } \\
\hline
\end{tabular}

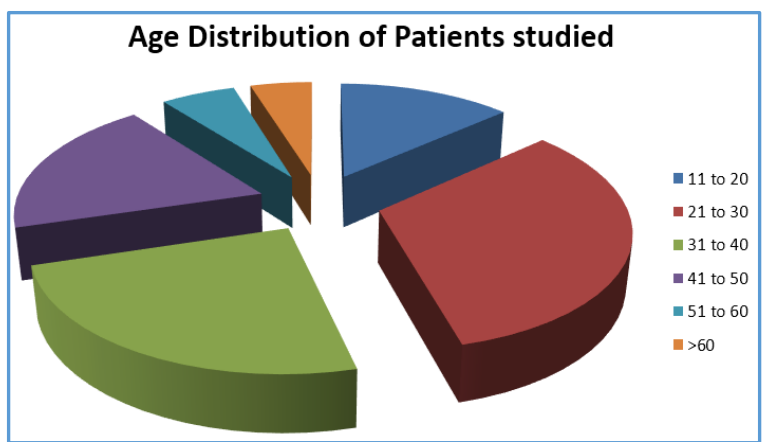

Patient's Age Group Ranged between 15 - 75 Years. Maximum Number of Patients were between 21 - 30 Years

\begin{tabular}{|c|c|c|}
\hline Sex & Number & Percentage \\
\hline Male & 37 & 35.6 \\
\hline Female & 67 & 64.4 \\
\hline Total & $\mathbf{1 0 4}$ & $\mathbf{1 0 0 . 0}$ \\
\hline \multicolumn{2}{|c|}{ Table 2. Sex Distribution of Patients Studied }
\end{tabular}

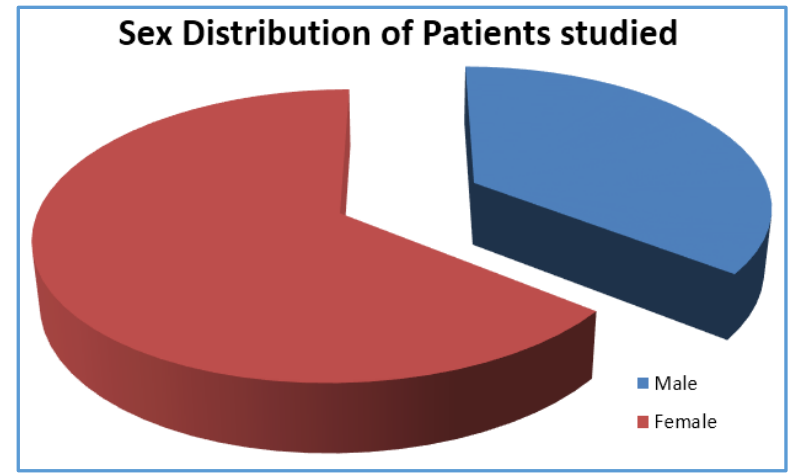

It is Observed that about $2 / 3^{\text {rd }}$ of Patients were Females and $1 / 3^{\text {rd }}$ were Males 


\begin{tabular}{|c|c|c|}
\hline Complaints & Number & Percentage \\
\hline Headache & 54 & 51.9 \\
\hline Nasal Discharge & 52 & 50.0 \\
\hline Nasal Obstruction & 43 & 41.3 \\
\hline Swelling & 2 & 1.9 \\
\hline \multicolumn{2}{|c|}{ Table 3. Chief Complaints } \\
\hline
\end{tabular}

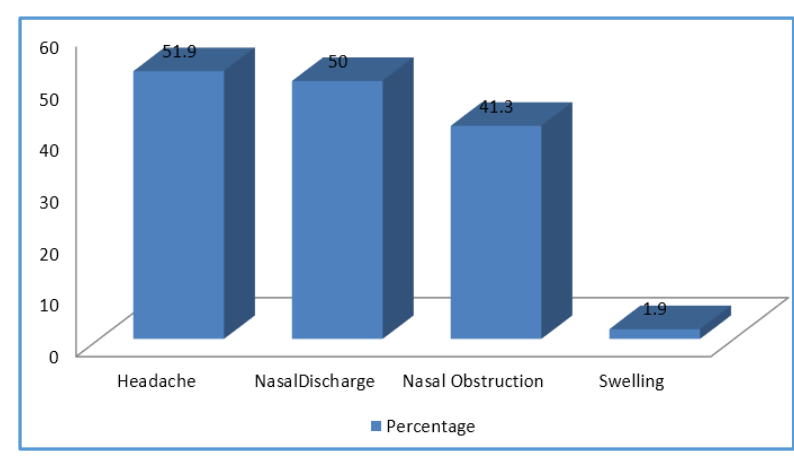

Headache was found to be Most Common Symptoms, i.e. $51.9 \%$ followed by Nasal Discharge

\begin{tabular}{|c|c|c|}
\hline Investigations & Number & Percentage \\
\hline \multicolumn{3}{|l|}{ DNS } \\
\hline No & 53 & 50.9 \\
\hline Left & 21 & 20.2 \\
\hline Right & 30 & 28.8 \\
\hline Total & 51 & 49 \\
\hline \multicolumn{3}{|l|}{ Concha Bullosa } \\
\hline No & 75 & 72.1 \\
\hline Left & 11 & 10.6 \\
\hline Right & 14 & 13.5 \\
\hline Bilateral & 4 & 3.8 \\
\hline Total & 29 & 27.9 \\
\hline \multicolumn{3}{|l|}{ OMU Obstruction } \\
\hline No & 31 & 29.8 \\
\hline Left & 15 & 14.4 \\
\hline Right & 14 & 13.5 \\
\hline Bilateral & 44 & 42.3 \\
\hline Total & 73 & 70.2 \\
\hline Table 4 & Anatomic & ants \\
\hline
\end{tabular}

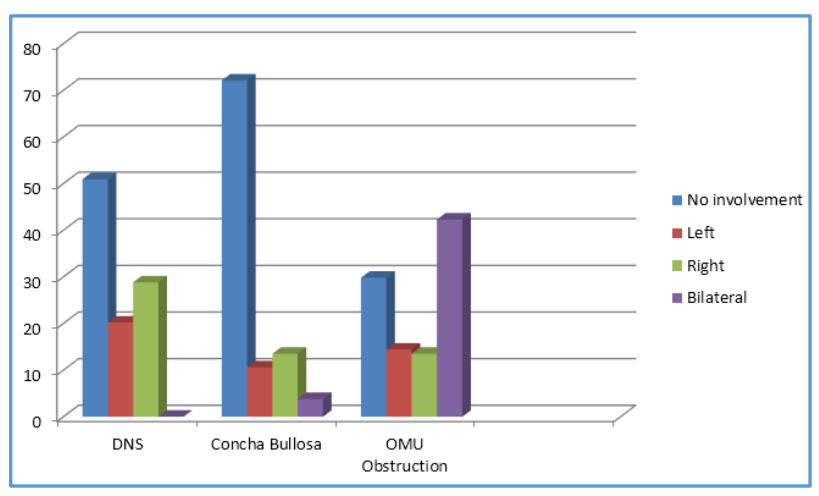

CT Findings showed DNS (Deviated Nasal Septum) in 49\%

Cases. Concha Bullosa in 27.9\%, OMU Obstruction in 70.2\% (Bilateral Cases Common)

\begin{tabular}{|c|c|c|}
\hline Sinus & Number & Percentage \\
\hline Maxillary & 94 & 88.5 \\
\hline Anterior Ethmoid & 82 & 79.2 \\
\hline Posterior Ethmoid & 76 & 71.1 \\
\hline Frontal & 56 & 52.9 \\
\hline Sphenoid & 46 & 45.2 \\
\hline \multicolumn{2}{|c|}{ Table 5. Sinus Diseased } \\
\hline
\end{tabular}

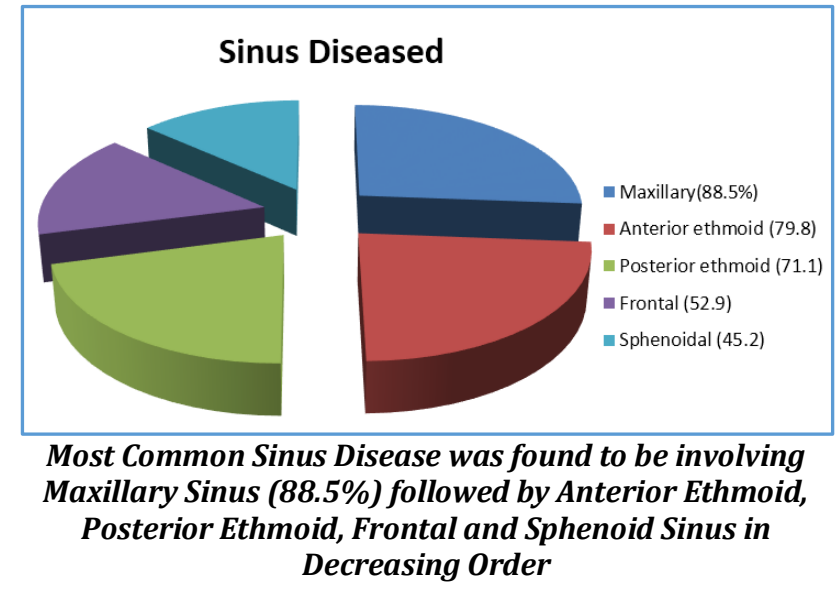

\section{DISCUSSION}

In this era of advanced science and technology, Computed Tomography (CT) is considered to be the optimum imaging method for demonstration of simple inflammatory disease to lethal malignant lesions involving paranasal air sinuses. Previously, it has been found that plain x-ray has poor correlation with CT. Clinical assessment along with CT findings of PNS disease helps to further investigate PNS disease refractory to medical therapy, as for example evaluation of the osteomeatal complex anatomy, which is not possible with plain x-ray. Removal of disease part in osteomeatal complex region is the basic principle of FESS (Functional Endoscopic Sinus Surgery), which is best appreciated by CT.

In this study patients, age group was between 15 to 75 years. Maximum number of patients (32.7\%) were found to be between 21 to 30 years' age group and is similar to the results of Venkatachalam, Pravahakars, Jagram Verma and Rashmi Tiwari.

Approximately, $2 / 3^{\text {rd }}$ were females and $1 / 3^{\text {rd }}$ were males. Consistent with works of Gliklick RE, Rashmi Tiwari but Jagram Verma showed ratio of 1: 1, while Prashant Gupta showed ratio of 1.3: 1 . DNS was found in 51 of 104 patients (49\%). Right sided was more common as seen in works of Sarabpreet Singh(11) and Rashmi Kandukuri. Concha bullosa was found in 29 patients in literature, it varied between $16 \%$ - 53\% as seen with findings of Dua K (16\%) and Babble RW (53\%). OMU pattern was observed in $73(70.2 \%)$ patients unlike found in works of Dua K (88\%).

Maxillary sinus was most commonly involved (90.4\%, i. e. 94 patients) followed by Anterior Ethmoid Sinus, Posterior Ethmoid Sinus, Frontal Sinus and Sphenoid Sinus. Studies in literature observed involvement of Anterior Ethmoid Sinus $(88 \%)$ as by works of Dua K and Kelkar AA (66\%) followed by Maxillary Sinus more common.

Variations in our study may be due to environmental and regional differences (Coastal belt of Odisha). Also, the climatic condition is hot and humid, and eating habits may also play a role for this variation. This study was helpful in studying the symptoms of the PNS disease/ inflammatory conditions and correlating them with main anatomical variants as well as the commonest sinus involvement seen in population of Odisha.

\section{Limitations}

This study evaluates only symptomatic patients; hence, no correlation between symptomatic and asymptomatic patient. Also, correlation of anatomical CT abnormality like Concha 
Bullosa, OMU Obstruction and Deviated Nasal Septum could not be stressed upon without the control group.

\section{CONCLUSION}

This was the prospective correlation descriptive clinical study carried out on 104 symptomatic Paranasal Sinus involvement patients who underwent CT PNS. Most patients are in $2^{\text {nd }}-3^{\text {rd }}$ decades of their life with male-to-female ratio of 1:2. Most common complaint was found to be headache and least being swelling. On evaluating patient with CT PNS, most common sinus to be involved was Maxillary Sinus and Sphenoid Sinus was least commonly affected.

To summarise, this study proved CT to be superior over clinical evaluation of symptomatic patients for diagnosis and further planning of management in cases of paranasal sinus involvement. CT provides anatomical details and true local extent of disease. CT is now well established as an alternative to standard radiographic techniques. CT evaluation in symptomatic patients helps in planning early and further treatment modality.

\section{REFERENCES}

[1] Zinreich SJ. Paranasal sinus imaging. OtolaryngologyHead Neck Surgery 1990;103(5):863-9.

[2] Singh IB, Pal GP. Human embryology. $7^{\text {th }}$ edn. London: Mac Millan India Ltd., 2003: p. 144-6.
[3] Van Alyea OE. Sphenoid sinus. Anatomic study, with consideration of the clinical significance of the structural characteristics of the sphenoid sinus. Arch Otolaryngo Head \& Neck Surgery 1941;34(2):225-53.

[4] Chow JM, Mafee MF. Radiological assessment of preoperative endoscopic sinus surgery. OCNA 1989;22(4):691-701.

[5] Schatz CJ, Becker TS. Normal CT Anatomy of paranasal sinuses. RCNA 1984;22(1):107-18.

[6] Sperber GH. Applied anatomy of maxillary sinus. Journal Can Dent Assoc 1980;46(6):381-6.

[7] Davis WE, Templer J, Parsons DS. Anatomy of para nasal sinuses. OCNA 1996;29(1):57-74.

[8] Stranding S. Gray's Anatomy. The anatomical basis of clinical practice, expert consult. 40th edn. Churchill Livingstone 2008: p. 556-9.

[9] Beale TJ, Madani G, Morley SJ. Imaging of paranasal sinuses and nasal cavity: normal anatomy and clinically relevant anatomical variants. Semin Ultrasound CT MR 2009;30(1):2-16.

[10] Cashman EC, MacMohan PJ, Smyth D. CT scan of PNS before functional endoscopic sinus surgery. World J Radial 2011;3(8):199-204.

[11] Kanwar SS, Mital MM, Gupta PK, et al. Evaluation of paranasal sinus disease by computed tomography and its histopathological correlation. Journal of Oral and Maxillofacial Radiology 2017;5(2):46-52. 